\title{
PENGARUH VARIASI JUMLAH PENGGUNAAN RSS DAN NBR TERHADAP SIFAT ROL KARET MESIN CETAK
}

\author{
Hadi Musthofa ${ }^{1}$, Prayitno $^{1)}$, Bambang Priyono ${ }^{1)}$ dan Dwi Wahini Nurhajati ${ }^{1)}$
}

\begin{abstract}
INTISARI
Tujuan penelitian adalah untuk mendapatkan perbandingan terbaik penggunaan karet alam (RSSI) dengan karet nitril (NBR) dalam pembuatan rol karet mesin cetak. Perbandingan karet alam/karet nitril yang digunakan : 100/0, 90/10, 80/20, 70/30, 60/40, 50/50, 40/60, $30 / 70,20 / 80,10 / 90$. Hasil pengujian secara kimia maupun fisika menunjukkan bahwa kompon dengan perbandingan karet alam dan nitril 50/50 memenuhi persyaratan SNI.05-2227-1991 Rol Karet Mesin Cetak. Sifat fisis kompon terbaik sebagai berikut : tegangan putus 5,18 N/ $\mathrm{mm}^{2}$, perpanjangan putus $446,91 \%$, kekerasan 32 shore A., pampat tetap $4,11 \%$, perubahan tegangan putus, perpanjangan putus dan kekerasan setelah pengusangan berturut-turut adalah $23,36 \%, 21,96 \%$ dan 1,22 shore A, sedangkan perubahan volum dalam $\mathrm{NaOH}$. oli, $\mathrm{HCl}$ dan dalam iso oktan berturut-turut adalah $2,41 \%, 2,96 \%, 4,67 \%$ dan $3,14 \%$.
\end{abstract}

\begin{abstract}
The aim of this research was to find the best ratio of natural rubber (RSSI) and nitrile rubber (NBR) were 100/0, 90/10, 80/20, 70/30, 60/40, 50/50, 40/60, 30/70, 20/80, 10/90. Physical and chemical testing result showed that compound by using natural and nitrile rubber in comparasion of 50/50, could meet the requirments of SNI. No. 05-2227-1991 Rubber Roll for Printing. The physical properties of the best compound were tensile strength $5,18 \mathrm{~N} / \mathrm{mm}^{2}$ elongation at break $446,91 \%$, hardness 32 shore A, compression set $4,11 \%$. Change in tensile strength elongation at break and hardness after aging were $23,36 \%, 21,96 \%$ and 1,33 shore $\mathrm{A}$, respectivly, whereas volume change after immersion in $\mathrm{NaOH}, \mathrm{HCl}$, oil and iso octane were $2,41 \%, 4,67 \%, 2,76 \%$ and $3,14 \%$ respectively.
\end{abstract}

\section{PENDAHULUAN}

Rol karet merupakan salah satu produk karet yang banyak dipergunakan keperluan percetakan. Sesuai dengan penggunaannya maka rol karet untuk mesin cetak dituntut dapat memenuhi persyaratan sebagaimana yang telah ditetapkan dalam SNI.05-2227-1991, Rol Karet Mesin Cetak. Tujuan penelitian ini adalah untuk mendapatkan perbandingan terbaik penggunaan karet alam dengan karet sintetis nitril dalam pembuatan rol karet mesin cetak. Dalam pembuatan rol karet agar diperoleh kualitas yang baik dan memenuhi persyaratan yang ditentukan, ada beberapa faktor yang perlu diperhatikan antara lain macam bahan yang dipergunakan, komposisi kompon, kondisi proses dan homogenitas kompon.

Sesuai dengan penggunaannya rol karet untuk mesin cetak sering berhubungan dengan minyak, maka dikehendaki sifat ketahanannya terhadap minyak dan juga pelarut yang

1) Balai Besar Penelitian dan Pengembangan Industri Barang Kulit, Karet dan Plastik Yogyakarta 
umumnya digunakan untuk tinta. Oleh sebab itu bahan yang digunakan harus dari karet yang mempunyai ketahanan terhadap tinta (Gupta BS). Bahan baku rol karet untuk mesin cetak dapat berupa karet alam maupun karet sintetis atau campuran keduanya. Karet sintetis yang banyak dipakai pada pembuatan rol karet untuk mesin cetak adalah berupa karet nitril, karena sifatnya yang tahan terhadap minyak dan karet nitril dapat didefinisikan secara luas sebagai kopolimer diena dengan unsaturated nitrile.

Pada saat ini yang banyak tersedia di pasaran adalah kopolimer dari butadiena dan akrilo nitril, butadiena sendiri merupakan hidrokarbon tidak jenuh dengan empat molekul karbon yang mempunyai dua ikatan rangkap (Ridha Arizal, 1994) serta mempunyai berat molekul 54.

Akrilo nitril mempunyai struktur $\mathrm{C}_{3} \mathrm{H}_{3} \mathrm{~N}$ atau dapat juga sebagai ikatan dua atom karbon dengan ikatan rangkap yang mana gugus cianidanya disubstitusi oleh atom hidrogen, dengan demikian akrilo niril dapat diartikan pula sebagai mononer vinil yang kadang-kadang disebut vinil sianida dan mempunyai berat molekul monomer tersebut hampir sama. Proporsi secara berat pada prakteknya sama dengan proporsi pada molekulnya, sehingga bila ada pernyataan bahwa perbandingan butadiena dan akrilonitril $2: 1$ ini merupakan perbandingan berdasarkan berat molekul (Dingra KC).

Karet nitril (NBR) mempunyai sifat utama yaitu tahan terhadap minyak dan ketahanan terhadap minyak ini diartikan sebagai kemampuan karet vulkanisai untuk tetap pada sifat aslinya setelah kontak dengan minyak. Karet nitril bisa terdapat dalam beberapa grade dan ketahanannya terhadap minyak didasarkan pada kandungan akrilonitril polimernya. Pada umumnya grade dibedakan menjadi kandungan akrilonitril tinggi, medium dan rendah. Polimer dengan akrilonitril tinggi digunakan bilamana kompon karet yang digunakan benarbenar tahan terhadap minyak, medium grade digunakan jika barang karetnya dikehendaki banyak berhubungan dengan minyak yang kandungan aromatiknya rendah atau pengembangan tidak diisyaratkan terlalu besar dan grade dengan kandungan akrilonitril rendah digunakan jika produk karetnya dikehendaki mempunyai fleksibilitas baik pada suhu rendah (Anonim, 1993).

Dalam pembuatan kompon karet, selain bahan baku diperlukan juga bahan pembantu seperti penggunaan sulfur (Abednego J.G., 1994) merupakan bahan pemvulkanisasi yang mempunyai kecenderungan membentuk gumpalan dipakai dalam bentuk lapis permukaan sehingga harus halus dan murni serta bebas dari campuran bahan lain. Untuk mempercepat proses vulkanisasi perlu ditambahkan bahan pencepat berupa mercapto benzo thiazole (MBT), mercapto benzo thiazole disulfide (MBTS), tetra methyl thiuram (TMT). Penggunaan bahan pencepat akan efektif bila ditambahkan bahan pengaktif berupa $\mathrm{ZnO}$ dan asam stearat sehingga waktu vulkanisasinya berkurang.

Selama pemanasan untuk menghidarkan atau mencegah terjadinya kerusakan perlu ditambahkan bahan antioksidasi yang membuat reaksi oksida oleh oksigen udara atau oksidasi karena pengaruh panas pada saat dilakukan komponding (Suharto, 1994). Bahan pengisi yang ditambahkan untuk memperbaiki sifat produk akhir yaitu karbon hitam, (Krisna, SB, 1994) untuk memudahkan bahan pengisi dengan bahan lain, perlu ditambahkan bahan pelunak seperti minyak mineral (Gupta BS), asam stearat dan bahan yang dapat larut dalam karet, tidak berbahaya jika ditambahkan dalam jumlah yang sesuai, tapi dapat menyebabkan terjadinya trouble jika dalam jumlah berlebih. Bahan pelunak lainnya yang berupa petroleum jelly, coumaron resin, chlor mineral rubber biasa digunakan dalam formulasi kompon 
karet, phenyl beta nephylamina (Nonox B) dan Aceton diphenilamine condensation products (Nonox B, Nonox BC) merupakan antioksidan yang memuaskan untuk produk yang berwarna hitam atau warna gelap lainnya. Untuk rol warna putih atau warna yang terang anti oksidan tipe styrenates phenol (Nonox Sp) banyak digunakan.

\section{BAHAN DAN METODA PENELITIAN}

\section{Bahan Penelitian}

Bahan untuk penelitian pengaruh variasi jumlah RSS dan NBR dalam pembuatan rol karet mesin percetakan terdiri atas bahan baku dan bahan pembantu dengan rincian sebagai berikut : karet alam (RSSI), karet nitril (NBR), asam stearat, $\mathrm{ZnO}$, carbon black, naphthenic oil, AOSP, MBTS, TMT, belerang, $\mathrm{NaOH}, \mathrm{HCl}$, oli dan iso oktan.

Komposisi kompon yang dipergunakan dalam melaksanakan penelitian disajikan pada tabel :

Tabel 1. Komposisi kompon karet rol mesin cetak

\begin{tabular}{|l|c|c|c|c|c|c|c|c|c|c|}
\hline \multirow{2}{*}{ Bahan (phr) } & \multicolumn{10}{|c|}{ FORMULA } \\
\cline { 2 - 11 } & I & II & III & IV & V & VI & VII & VIII & IX & X \\
\hline RSS & 100 & 90 & 80 & 70 & 60 & 50 & 40 & 30 & 20 & 10 \\
NBR & - & 10 & 20 & 30 & 40 & 50 & 60 & 70 & 80 & 90 \\
Asam stearat & 1 & 1 & 1 & 1 & 1 & 1 & 1 & 1 & 1 & 1 \\
ZnO & 5 & 5 & 5 & 5 & 5 & 5 & 5 & 5 & 5 & 5 \\
Carbon black & 10 & 10 & 10 & 10 & 10 & 10 & 10 & 10 & 10 & 10 \\
Naphthenis oil & 30 & 30 & 30 & 30 & 30 & 30 & 30 & 30 & 30 & 30 \\
AOSP & 1 & 1 & 1 & 1 & 1 & 1 & 1 & 1 & 1 & 1 \\
MTBS & 0,5 & 0,5 & 0,5 & 0,5 & 0,5 & 0,5 & 0,5 & 0,5 & 0,5 & 0,5 \\
TMT & 2,5 & 2,5 & 2,5 & 2,5 & 2,5 & 2,5 & 2,5 & 2,5 & 2,5 & 2,5 \\
Belerang & 0,25 & 0,25 & 0,25 & 0,25 & 0,25 & 0,25 & 0,25 & 0,25 & 0,25 & 0,25 \\
\hline
\end{tabular}

Keterangan : phr $=$ per hundred rubber

\section{Peralatan Penelitian}

Peralatan penelitian variasi jumlah RSS dan NBR terdiri atas two roll mill, hydraulic press, neraca analitik, oven, alat uji tegangan putus, kekerasan, pampat tetap dan alat ukur tebal.

\section{Cara Penelitian}

Pembuatan kompon karet untuk rol mesin percetakan menggunakan two roll mill melalui tahapan sebagai berikut : bahan ditimbang sesuai dengan formulasi yang telah ditentukan. Bahan baku karet alam yang sudah ditimbang dimasukkan dalam two roll mill diproses sampai plastis, selanjutnya ditambah karet sintetis dan digiling kembali sehingga didapatkan masa plastis. Setelah diproses masa yang plastis dari bahan baku karet kemudian ditambah secara berturut-turut bahan pelunak, bahan pengisi, bahan anti oksidan, bahan pengaktif, bahan pencepat dan terakhir ditambah belerang. Hasil pencapuran berupa kompon karet sebelum dicetak dikondisikan terlebih dahulu selama 24 jam. Hasil komponding dalam 
bentuk slab (lembaran) selanjutnya divulkanisasi pada suhu $150^{\circ} \mathrm{C}$ dan tekanan $150 \mathrm{~kg} /$ $\mathrm{cm}^{2}$. Slab yang dihasilkan sebelum diuji dikondisikan terlebih dahulu dalam ruang pada suhu $27^{\circ} \pm 2^{\circ} \mathrm{C}$ dan kelembaban relatif $65 \pm 5 \%$ selama minimal 16 jam.

Sla $\bar{b}$ hasil vulkanisasi diuji sifat fisika dan kimia meliputi : perpanjangan putus, pampat tetap, kekerasan dan perubahan sifat fisis setelah pengusangan serta perubahan volume dalam $\mathrm{NaOH}$, oli, $\mathrm{HCl}$ dan iso oktan sesuai dengan SNI. 05-2227-1991 Rol karet mesin cetak.

\section{HASIL DAN PEMBAHASAN}

Hasil uji vulkanisat karet disajikan dalam tabel 2.

\section{Tabel 2. Hasil pengujian vulkanisat karet rol mesin cetak}

\begin{tabular}{|c|c|c|c|c|c|c|c|c|c|c|c|c|}
\hline \multirow[t]{2}{*}{ No. } & \multirow[t]{2}{*}{ Jenis Uji } & \multicolumn{10}{|c|}{ FORMULA } & \multirow{2}{*}{$\begin{array}{c}\text { SNI.05- } \\
2227-1991\end{array}$} \\
\hline & & I & II & III & $\mathrm{N}$ & $\mathrm{V}$ & V & VII & VIII & IX & $\bar{X}$ & \\
\hline 1. & Tegangan putus $(\mathrm{N} / \mathrm{mm} 2)$ & 11,44 & 11,44 & 7,5 & 8,38 & 5,45 & 5,18 & 2,3 & 1,44 & 1,93 & 1,28 & $\min .2,4$ \\
\hline 2. & Perpanjangan putus (\%) & 737,78 & 815,41 & 719,41 & 689,68 & 561,11 & 446,91 & 456,79 & 300,62 & 360,49 & 519,7 & $\min .400$ \\
\hline 3. & Kekerasan Shore A & 31,67 & 33 & 33,67 & 34,33 & 31 & 32 & 30 & 30 & 30 & 30 & $30 \pm 5$ \\
\hline 4. & Pampat tetap $\%$ & 4,47 & 1,99 & 3,96 & 3,07 & 3,19 & 4,11 & 2,81 & 4,4 & 9,91 & 9,91 & $\max .10$ \\
\hline 5. & Perubahan setelah pengusangan & & & & & & & & & & & \\
\hline & - Tegangan putus $\%$ & $-36,02$ & $+1,4$ & $+54,93$ & $-0,48$ & $+9,94$ & $-23,36$ & $+17,5$ & -8 & $+53,89$ & $+42,19$ & $\max .-30$ \\
\hline & - Perpanjangan putus $\%$ & $-34,71$ & $-15,75$ & $-6,52$ & $-8,71$ & $-13,25$ & $-21,96$ & $-31,48$ & $-9,4$ & $-13,26$ & $+46,64$ & $\max .-30$ \\
\hline & - Kekerasan Shore A & 5,33 & 2 & 1 & 1,34 & 4,33 & 3,33 & 1,33 & 0,33 & 5,67 & 6,48 & +5 \\
\hline 6. & $\begin{array}{l}\text { Perubahan volume dalam } \\
-\mathrm{NaOH}(\%)\end{array}$ & 943 & 85 & 9.13 & 5.21 & 4,11 & 2,41 & 3,8 & 3.56 & 2,96 & 2 & $\max .2,5$ \\
\hline & - Oli (\%) & 50,63 & 50,35 & 48 & 36,00 & 10,36 & 2,96 & 18,07 & 34,19 & 14,47 & 1,89 & +5 \\
\hline & $\mathrm{HCl}(\%)$ & 8,63 & 7,40 & 8,79 & 8,79 & 6,34 & 4,67 & 6,78 & 5,55 & 2,69 & 2,53 & $\max .15$ \\
\hline & -Isookatan (\%) & 72,21 & 61,97 & 51,23 & 51,23 & 25,39 & 3,14 & 14,42 & 6,78 & 5,55 & 2,53 & +8 \\
\hline
\end{tabular}

Data hasil pengujian menunjukkan bahwa variasi perbandingan jumlah karet alam (RSS) dan karet nitril (NBR) mengakibatkan perubahan sifat-sifat fisika serta sifat kimia kompon karet rol mesin cetak.

1. Tegangan Putus

Penambahan karet nitril (NBR) mulai 20 phr cenderung menurunkan tegangan putus vulkanisat karet. Dari analisa statistik ternyata bahwa penurunan tegangan putus berbeda nyata $(\mathrm{P} \leq 0,05)$. Penurunan ini disebabkan sifat dasar karet nitril mempunyai tegangan putus yang lebih rendah dari pada karet alam. Kompon yang berisi karet nitril lebih dari 60 phr sifat tegangan putusnya tidak memenuhi SNI. 05-2227-1991 Rol karet mesin cetak.

2. Perpanjangan Putus

Perpanjangan putus kompon karet yang dibuat cenderung turun dengan penambahan karet nitril mulai $20 \mathrm{phr}$, dan penurunan ini terlihat secara nyata $(\mathrm{P} \leq 0,05)$ terjadi mulai kompon III sampai dengan kompon IX.

Penurunan sifat perpanjangan putus ini dikarenakan karet nitril mempunyai perpanjangan putus yang lebih rendah dari karet alam. Perpanjangan putus tertinggi $(815,41 \%)$ dicapai oleh kompon yang mempunyai komposisi karet alam 90 phr dan karet nitril 10 phr. Kompon yang tidak memenuhi SNI. 05-2227-1991 adalah kompon VIII yang berisi karet nitril 70 phr dan kompon IX yang berisi karet nitril 80 phr. 
3. Kekerasan

Kekerasan kompon karet yang diperoleh dari hasil penambahan karet nitril ternyata tidak menunjukkan perbedaan yang nyata $(\mathrm{P} \leq 0,05)$. Hal ini berarti bahwa penambahan karet sintetis (karet nitril) pada karet alam tidak mempengaruhi kekerasan kompon karet.

4. Pampat Tetap

Sifat pempat tetap karet alam lebih besar dari pada karet nitril, oleh karena itu kenaikan kandungan karet nitril dalam kompon karet menurunkan sifat pampat tetap. Nilai pampat tetap semua kompon yang dibuat memenuhi SNI. 05-2227-1991 Rol karet mesin cetak.

5. Perubahan sifat fisika setelah pengusangan.

Kompon karet jika dikenai perlakuan pengusangan yaitu pemanasan pada suhu $100^{\circ} \mathrm{C}$ dalam waktu 70 jam akan mengalami perubahan sifat fisika meliputi :

- Tegangan putus

Kompon yang hanya berisi karet alam (kompon I) mengalami penurunan sifat tegangan putus terbesar (36,02\%). Kompon yang bersisi karet nitril setelah pengusangan ternyata nilai tegangan putusnya naik, hal ini mungkin dikarenakan oleh waktu curingnya yang belum sempurna, sehingga justru dengan perlakuan pemanasan selama 70 jam pada suhu $100^{\circ} \mathrm{C}$ akan mematangkan kompon.

- Perpanjangan putus

Uji pengusangan ternyata menurunkan sifat perpanjangan putus kompon. Penurunan terbesar $(34,71 \%)$ terjadi pada kompon yang tidak ditambah karet nitril, karena karet alam relatif tidak tahan terhadap pemanasan.

- Kekerasan

Vulkanisat kompon karet setelah uji pengusangan menunjukkan kenaikan sifat kekerasan. Ini berarti kompon mengalami proses pematangan lebih lanjut. Kenaikan kekerasan tertinggi $(6,18 \%)$ dicapai oleh kompon yang berisi karet nitril 90 phr.

6. Pengaruh bahan kimia

Perubahan volume kompon karet setelah dilakukan perendaman di dalam $\mathrm{NaOH} 20 \%$, $\mathrm{HCl} 20 \%$, iso oktan selama 70 jam pada suhu kamar, dan di dalam oli selama 70 jam pada suhu $100^{\circ} \mathrm{C}$ dapat dilihat pada tabel 2

Tabel 2 memperlihatkan bahwa perubahan volume terkecil 2\% (di dalam $\mathrm{NaOH}$ ), 2,53\% (di dalam $\mathrm{HCl}$ ). 1,89\% (di dalam oli) dan 2,53\% (di dalam iso oktan) terjadi pada kompon $\mathrm{X}$ yang berisi karet nitril $90 \mathrm{phr}$.

Data uji juga memperlihatkan bahwa makin tinggi kandungan karet nitril maka perubahan volume akibat perendaman dalam $\mathrm{NaOH}, \mathrm{HCl}$, oli dan iso oktan makin kecil. Hal ini dikarenakan karet nitril mempunyai sifat yang lebih tahan terhadap basa, asam, minyak dan iso oktan dibanding karet alam.

Dari tabel 2 terlihat bahwa kompon yang memenuhi semua persyaratan mutu seperti tertulis dalam SNI. 05-2227-1991 Rol karet mesin cetak adalah kompon VI yang mempunyai komposisi terdiri dari karet alam (RSSI) 50 phr dan karet nitril (NBR) 50 phr.

\section{KESIMPULAN}

Dari hasil penelitian pembuatan kompon karet rol mesin cetak dapat disimpulkan bahwa : a. Penambahan karet nitril (NBR) pada karet alam (RSS) dalam campuran kompon menurunkan sifat tegangan putus; perpanjangan putus, dan pampat tetap, namun tidak 
mempengaruhi kekerasan

b. Makin banyak karet nitril (NBR) menyebabkan kompon karet lebih tahan terhadap pengaruh $\mathrm{NaOH} 20 \%, \mathrm{HCl} 20 \%$, oli dan iso oktan.

c. Kompon dengan perbandingan karet alam (RSS) 50 bagian dan karet nitril (NBR) 50 bagian menunjukkan sifat kimia dan fisika yang memenuhi SNI.05-2227-1991 Rol karet mesin cetak yaitu tegangan putus $5,18 \mathrm{~N} / \mathrm{mm}^{2}$, perpanjangan putus $446,91 \%$, kekerasan 32 shore $\mathrm{A}$, pampat tetap $4,11 \%$, perubahan tegangan putus, perpanjangan putus dan kekerasan setelah pengusangan berturut-turut adalah $23,36 \%, 21,96 \%$ dan 1,22 shore A, sedangkan perubahan volume dalam $\mathrm{NaOH}$, oli, $\mathrm{HCl}$ dan dalam iso oktan berturutturut adalah $2,41 \%, 2,96 \%, 4,67 \%$ dan $3,14 \%$.

\section{DAFTAR PUSTAKA}

Anonim, 1993 Penelitian Penggunaan Parafinic Oil Pertamina Sebagai Processing Oil Dalam Pembuatan Kompon Karet Untuk Ban Dalam dan Lis Kaca Mobil BBKP.

Dingra KC, Rubber and Rubber Goods Industries, Delhi.

Gupta B.S., Rubber Processing Oil and Technology, Delhi.

Abednego J.G., 1994, Bahan Kimia Penyusun Kompon, BPTK Bogor.

Krisna Surya Buana, 1994, Proses Mastikasi dan Pencampuran Kompon, BPTK Bogor.

Ridha Arizal, 1994, Pengetahuan Dasar Elastomer, BPTK Bogor.

SNI.05-2227-1991, Rol Karet Mesin Cetak. Dewan Standardisasi Nasional.

Maurya, GP, 1981., Rubber Technology and Manufacture, Small Business Publication. New Delhi.

Suharto Honggo Kusumo, 1994, Desain Kompon, BPTK Bogor. 